\title{
Recognition and management of intra-abdominal hypertension and abdominal compartment syndrome; a survey among Dutch surgeons
}

\author{
Steven G. Strang ${ }^{1} \cdot$ Esther M. M. Van Lieshout $^{1} \cdot$ Roelof A. Verhoeven $^{1}$ • \\ Oscar J. F. Van Waes ${ }^{1} \cdot$ Michael H. J. Verhofstad ${ }^{1}$ IAH-ACS Study Group
}

Received: 19 October 2015 / Accepted: 14 January 2016 / Published online: 22 February 2016

(c) The Author(s) 2016. This article is published with open access at Springerlink.com

\begin{abstract}
Purpose Intra-abdominal hypertension (IAH) and Abdominal compartment syndrome (ACS) are relatively rare, but severe complications. Although many advances were made in recent years, the recognition and management remain subject of debate. The aim of this study was to determine the current state of awareness, knowledge and use of evidence-based medicine regarding IAH and ACS among Dutch surgeons.

Methods A literature-based and expert consensus survey was developed. One surgeon in every hospital in The Netherlands was asked to complete the online questionnaire.

Results Sixty of 87 (69\%) invited surgeons completed the questionnaire. Intra-abdominal pressure (IAP) was measured using intra-vesical methods by $55(98 \%)$ respondents. Diuretics $(N=38 ; 63 \%)$ and laparotomy $(N=33 ; 55 \%)$ were considered useful treatments for IAH or prevention of ACS by a majority. Only $16(27 \%)$ respondents used these guidelines in daily practice, and $37(62 \%)$ respondents are willing to do so. Although 35 (58 \%) surgeons agreed that IAH is only a symptom, not requiring treatment. Forty-one percent of experienced respondents suggested that prevalence of ACS remained unchanged. Nearly all respondents $(N=59 ; 98 \%)$ believed that open abdomen management
\end{abstract}

IAH-ACS study group members are listed under Acknowledgments.

Oscar J. F. Van Waes

o.vanwaes@erasmusmc.nl

Steven G. Strang

s.strang@erasmusmc.nl

1 Trauma Research Unit Department of Surgery, Erasmus MC, University Medical Center Rotterdam, P.O. Box 2040, 3000, CA, Rotterdam, The Netherlands improves patient outcomes, many $(N=46 ; 77 \%)$ confirm the high complications rate of this treatment.

Conclusion The definitions of IAH and ACS and the related diagnostic and therapeutic challenges are relatively well known by Dutch surgeons. Despite limited use of the evidence-based guidelines, the willingness to do so is high. Most respondents favor open abdomen treatment for patients with imminent ACS, despite the high complication rates associated with this treatment.

Keywords Intra-abdominal pressure $\cdot$ Intra-abdominal hypertension - Abdominal compartment syndrome ·

Management · Questionnaire

\section{Introduction}

Abdominal compartment syndrome (ACS) is a severe, but relatively rare complication. IAH is more common and can proceed into ACS in some of cases. Over recent years many advances regarding the recognition and management of ACS have been made. Nonetheless, randomized controlled trials on the subject are still scarce. Current management of ACS is based upon the up-to-date, evidence-based recommendations provided by the World Society of the Abdominal Compartment Syndrome (WSACS) [1]. The strength of these recommendations is of varying quality. As a result, the management of ACS is still subject of debate and differs across hospitals.

Multiple studies have been conducted to identify the then current state of awareness, knowledge and use of evidence-based medicine regarding IAH and ACS. One of the most noticeable findings of these studies was that the awareness of IAP measurements and treatment options of IAH and ACS was generally low [2-9]. In addition, cut-off 
points for treatment of ACS are poorly known or understood [3, 10-13]. There is little agreement on the indications for open abdomen treatment and what type of temporary abdominal closure devices should be used [14-18]. Most recent studies conclude that awareness among health care providers improved over recent years, but guidelines are still not uniformly applied or knowledge was inadequate [19-21].

The most recent survey was performed in 2010. Since then, new developments, such as the introduction of updated WSACS guidelines in 2013, may have improved outcome. Quality of previous questionnaires was variable. The response rates of these questionnaires ranged from 26 to $90 \%$. Other limitations were duration of more than 2 years and most studies were carried out by a wide variety of health care workers. Only six specifically focused on surgeons, yet surgeons ultimately decide whether or not to apply an open abdomen decompression $[2-4,8,14$, 15]. No comparable surveys have been performed in The Netherlands.

The primary aim of this study was to identify the current state of awareness, knowledge and use of evidence-based medicine regarding IAH and ACS among Dutch surgeons. Secondary aims were to identify the current annual number of ACS cases per hospital and, to assess outcome of ACS patients.

\section{Methods}

This questionnaire study was conducted and reported in accordance with the guidelines for survey research of Bennett et al. [22].

\section{Ethical statement}

The current study used data that were obtained from surgeons using a survey. The questionnaire was anonymous. An independent officer of data and privacy protection in our hospital reviewed the survey procedure and confirmed that participants' anonymity was protected. Since patients were not involved in the study, the institutional Medical Research Ethics Committee did not have to review the protocol.

\section{Questionnaire}

The questionnaire was based upon a previously published questionnaire by the WSACS study group [21]. Key questions were adopted and response options were added to make them more up-to-date. The questionnaire was drafted in Dutch and pretested by a panel of five experts and critically appraised on relevance, completeness, and style
(OJFVW, MHJV, RSB, DHB, and KAK). The final version of the structured questionnaire consisted of five parts with a total of 29 questions; one part for participant's information and four parts for questions related to (1) IAP measurement, (2) IAH, (3) ACS, (4) open abdomen treatment and abdominal closure techniques. The full questionnaire is available in English (Appendix 1).

\section{Selection of respondents}

Surgical department of all Dutch hospitals with ICU facilities $(N=87)$ was asked to provide the name of the surgeon with the most ICU affinity. If a hospital had multiple locations with ICU facilities, only one surgeon was selected. All named surgeons were approached by telephone and informed about the purpose and method of the survey. Since one surgeon in every hospital throughout the country was selected, the targeted group of surgeons was presumed a representative cross-section of the care which patients in The Netherlands receive. Dutch surgical departments are relatively well informed and the rate of evidence-based guideline implementation is high. The results of this survey are therefore applicable for to Western European standards. For this survey, a sample size calculation was considered unnecessary.

\section{Distribution of survey}

The questionnaire was distributed online using LimeSurvey software [Version 2.05+, LimeSurvey Project Team, Carsten Schmitz (2015), LimeSurvey Project Hamburg, Germany]. After obtaining verbal informed consent, a link to the questionnaire with unique and secure access codes was sent by email. This first invitation was sent on January 29, 2015. Reminders were sent every 2 weeks until the survey was closed on April 13, 2015. An opt-out link was clearly marked, the questionnaire could also be sent by mail or email if requested.

\section{Data}

Data were stored online by a secured function of the software used. Following survey closure, data were downloaded to an SPSS file. Questionnaires that were completed on paper were entered manually into the SPSS database. Only complete data sets were included in the analysis.

\section{Analysis}

All data were of categorical nature and are shown as numbers with corresponding percentages. Descriptive analysis was performed in SPSS version 21.0 (SPSS Statistics for Windows, Released 2012, Armonk, New York, IBM Corporation). No comparisons were made with previously 
performed surveys since differences between questionnaires and populations were considered too large.

\section{Results}

\section{Respondents}

Sixty surgeons completed the questionnaire (response rate: $69 \%$ ). Ten partial responses were excluded. Most respondents had a primary focus on trauma surgery $(N=29 ; 48 \%)$ or oncological surgery $(N=20 ; 33 \%$, Fig. 1$)$. The majority $(N=38 ; 63 \%)$ had over 10 years of surgical experience and more than half of respondents worked in a general teaching hospital $(N=34 ; 57 \%)$.

\section{Intra-abdominal pressure measurements}

IAP measurements were performed in 58 (96\%) of the hospitals. Forty-seven (78\%) respondents claimed to know the difference between IAH and ACS, and 57 (95\%) respondents had seen at least one patient with ACS.

Fifty-five $(98 \%)$ respondents use intra-vesical methods for IAP measurement. The largest group of respondents $(N=14 ; 25 \%)$ measures IAP three times daily on average (Fig. 2).

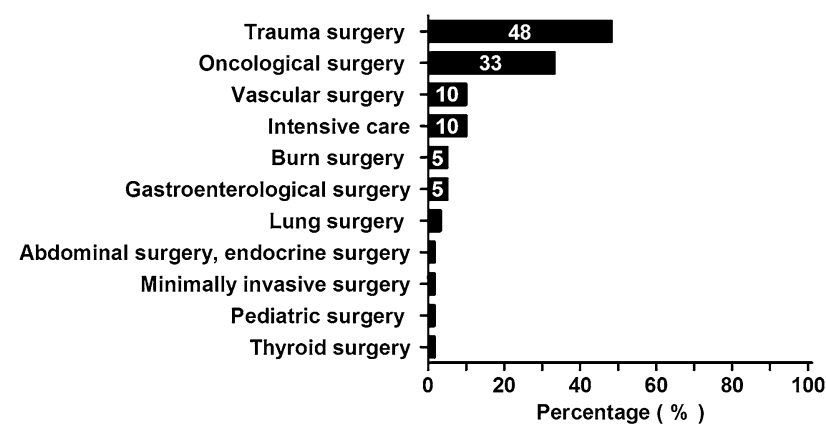

Fig. 1 Primary focus of respondents. Primary focus of respondents is arranged on the $y$-axis from highest to lowest frequency. Percentages of all respondents are shown in the bars

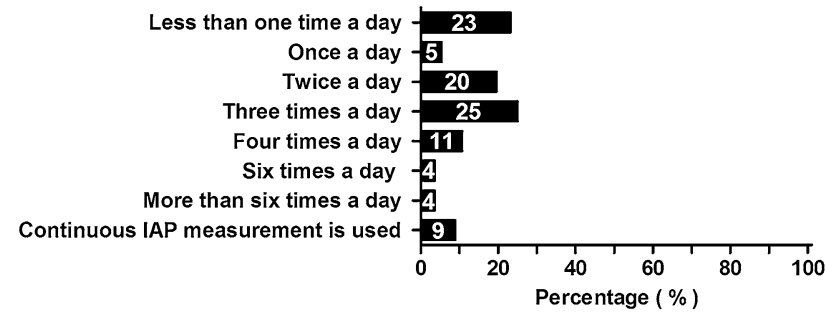

Fig. 2 Number of IAP measurements performed daily in the individual patient. Percentages of all respondents are shown in the bars

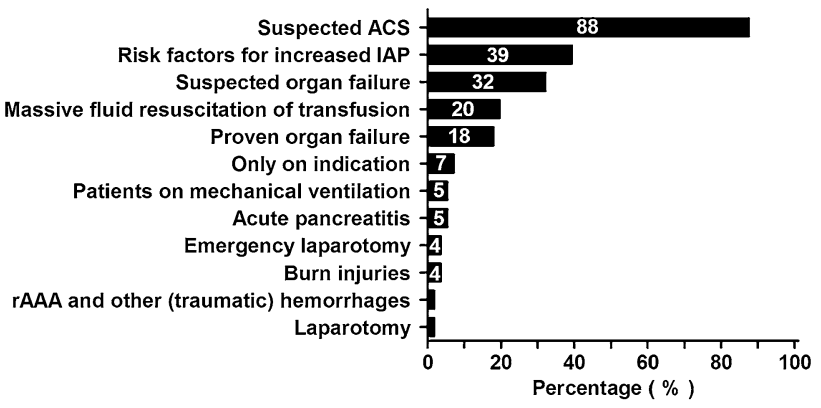

Fig. 3 Percentage of patients in which IAP measurements are performed more or less routinely (patients with or after a/an:). Percentages of all respondents are shown in the bars

Forty-nine $(88 \%)$ respondents wait with measuring of IAP until there is a clear suspicion for ACS, and 22 (39\%) respondents start measurements as soon as risk factor(s) for ACS are identified (Fig. 3).

\section{Intra-abdominal hypertension}

Forty-two $(70 \%)$ respondents claimed to use the definition of IAH as set by the WSACS (Table 1). Of the seven

Table 1 Used definition for IAH (not ACS)

\begin{tabular}{lrr}
\hline & $N$ & $\%$ \\
\hline An IAP of $\geq 12 \mathrm{mmHg}$, as stated by the WSACS & 42 & 70 \\
An IAP of $>18 \mathrm{mmHg}$ & 1 & 2 \\
An IAP of $>20 \mathrm{mmHg}$ & 1 & 2 \\
Ongoing or increasing IAP at multiple measurements & 1 & 2 \\
No definition & 15 & 25 \\
\hline
\end{tabular}

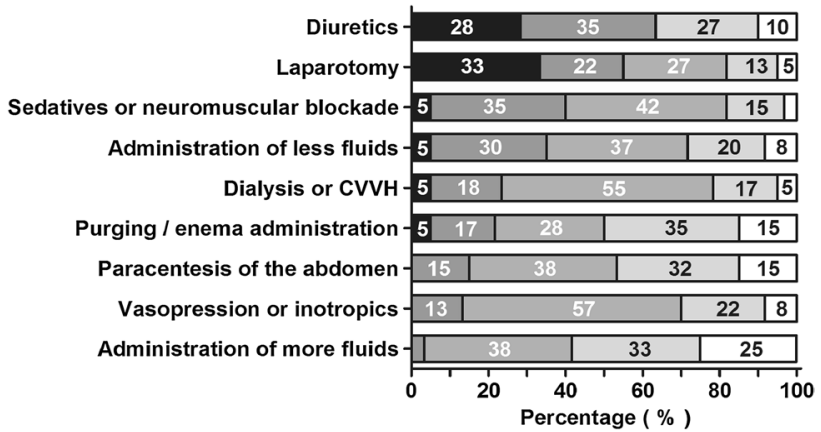

Fig. 4 Usefulness of treatments for IAH to prevent ACS. Therapy options are arranged from highest to lowest summed percentage of very useful and fairly useful. Percentages of all respondents are shown in the bars 


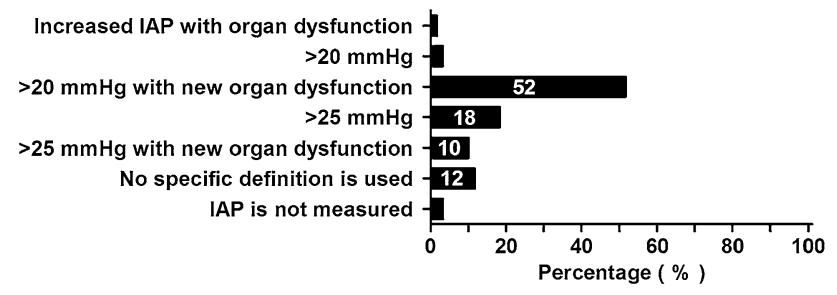

Fig. 5 Definition used for ACS (not IAH, an IAP of:). Percentages of all respondents are shown in the bars

Table 2 Use of WSACS guidelines and recommendations for treatment of abdominal compartment syndrome

\begin{tabular}{lrr}
\hline & $N$ & $\%$ \\
\hline This guideline is used & 16 & 27 \\
This guideline is not used, but respondent is willing to do so & 37 & 62 \\
$\begin{array}{l}\text { This guideline is not used because it presumably does not } \\
\text { improve the outcome of patients }\end{array}$ & 6 & 10 \\
There is no need for such a guideline & 1 & 2 \\
\hline
\end{tabular}

treatment options listed for IAH, only diuretics $(N=38$; $63 \%)$ and laparotomy $(N=33 ; 55 \%)$ were considered very useful or fairly useful by the majority of respondents (Fig. 4). Thirty-five (58\%) respondents agreed to the statement that IAH is only a symptom and as such needs no treatment.

\section{Abdominal compartment syndrome}

For ACS, the majority of respondents $(N=31,52 \%)$ used the definition as proposed by the WSACS (Fig. 5). It was noteworthy that $17(28 \%)$ respondents used a higher threshold for ACS.

Most respondents $(N=33 ; 55 \%)$ were not familiar with the WSACS guidelines for the treatment of ACS. Whereas $27(45 \%)$ respondents were familiar with the guidelines, only $16(27 \%)$ actually use them in daily practice. Another 37 (62\%) respondents is willing to do so in the future (Table 2). A minority $(N=6 ; 10 \%)$ disputes that the guidelines improve outcome of patients with ACS.

Eighteen $(30 \%)$ respondents answered that patients with ACS should be treated with surgical decompression in $76 \%$ to $100 \%$ of cases in their hospital (Fig. 6). Another $18(30 \%)$ indicated that this was done in $51-75 \%$ of cases.

The vast majority of respondents considered oliguria, ventilation pressure, acidosis, lactate, and cardiac output as relevant when deciding for a surgical abdominal decompression (Fig. 7). A large group ( $N=26$; $43 \%)$ stated that a superior indicator for surgical

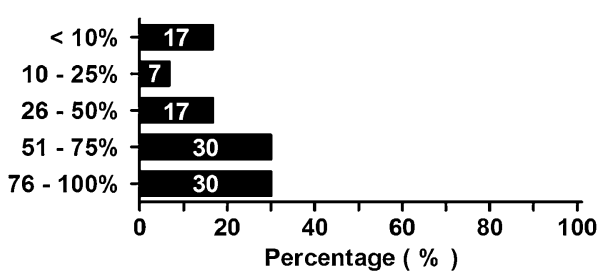

Fig. 6 Number of ACS patients per hospital, treated with a surgical abdominal decompression. Percentages of all respondents are shown in the bars

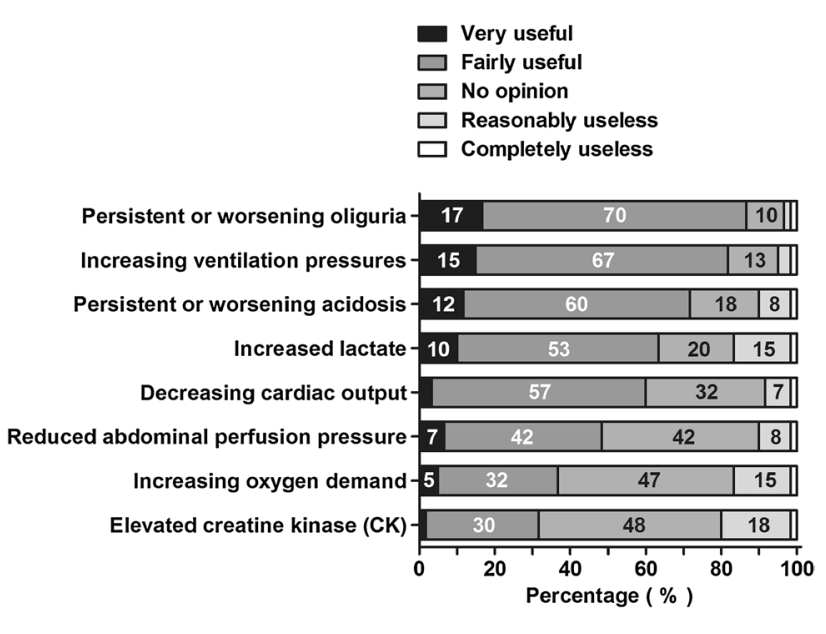

Fig. 7 Usefulness of factors in deciding for surgical abdominal decompression (in addition to intra-abdominal pressure). Factors are arranged from highest to lowest summed percentage of very useful and fairly useful. Percentages of all respondents are shown in the bars

decompression would be a useful addition into clinical practice (Table 3).

The mortality rate of patients with ACS who are not treated with surgical decompression was estimated between 26 and $50 \%$ by $18(30 \%)$ respondents and between 51 and $75 \%$ by $22(37 \%)$ respondents (Fig. 8). If patients with ACS were treated with surgical decompression, the largest group of respondents $(N=28 ; 47 \%)$ estimated a mortality rate of $10-25 \%$.

\section{Open abdomen treatment and abdominal closure techniques}

Fifty-three $(88 \%)$ respondents considered surgical abdominal decompression useful in the prevention of ACS (Table 4). However, the majority felt that ACS may not always be prevented.

The respondents were asked which factors would affect their decision whether or not to close the abdomen after surgical decompression. Most respondents answered that an increase in ventilation pressures is 
Table 3 Need for superior indicators of abdominal decompression (for example a serum marker of hypo-perfusion of abdominal organs)

\begin{tabular}{lrr}
\hline & $N$ & $\%$ \\
\hline Yes, there is a need for superior indicators & 26 & 43 \\
I do not know/no opinion & 26 & 43 \\
No, there is no need for superior indicators & 8 & 13 \\
\hline
\end{tabular}

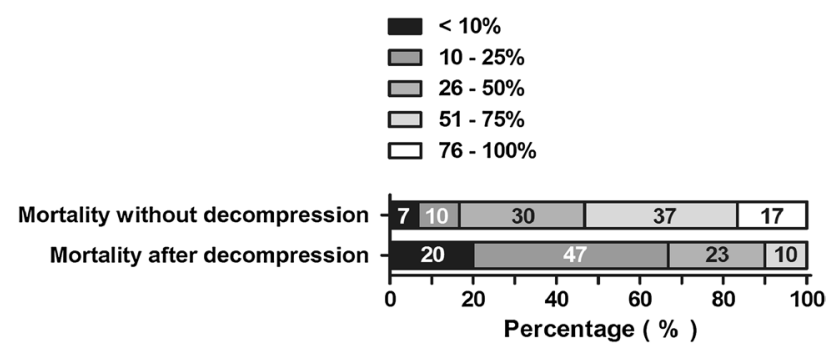

Fig. 8 Estimated mortality rate among patients with ACS. Percentages of all respondents are shown in the bars

either useful $(N=36 ; 60 \%)$ or very useful $(N=12$; $20 \%$ ) in this decision (Fig. 9). In addition, tension on the abdominal wall while closing the abdomen, planned reoperation, application of abdominal packings, hemodynamic instability at closure and visceral edema were also considered useful by the majority of the respondents.

If primary closure is not possible, several devices are available for temporary closure. Among the respondents, application of a Vicryl ${ }^{\circledR}$ mesh was the most popular method for temporary closure, chosen by 38 (63\%) respondents (Table 5). Many respondents selected multiple methods of temporary closure, 22 (37\%) respondents selected two methods and $18(30 \%)$ even selected three.

The largest group $(N=27 ; 45 \%)$ of respondents prefers definitive abdominal closure in multiple stages (Table 6). An almost equally large group $(N=26 ; 43 \%)$ prefers the component separation technique.

Almost all respondents $(N=59 ; 98 \%)$ believed that open abdomen management improves patient outcomes, of which the majority $(N=46)$ also acknowledged the high complication rate associated with open abdomen management (Table 7).

\section{Discussion}

This study is the first survey detailing awareness, knowledge, and use of evidence-based medicine and outcome regarding intra-abdominal hypertension and abdominal compartment syndrome among Dutch surgeons. The definitions of the WSACS are well known now, but the clinical
Table 4 Open abdominal treatment prevents ACS

\begin{tabular}{lcc}
\hline & $N$ & $\%$ \\
\hline Yes, always & 16 & 27 \\
Yes, but not always & 37 & 62 \\
I am not sure & 6 & 10 \\
No, never & 1 & 2 \\
\hline
\end{tabular}

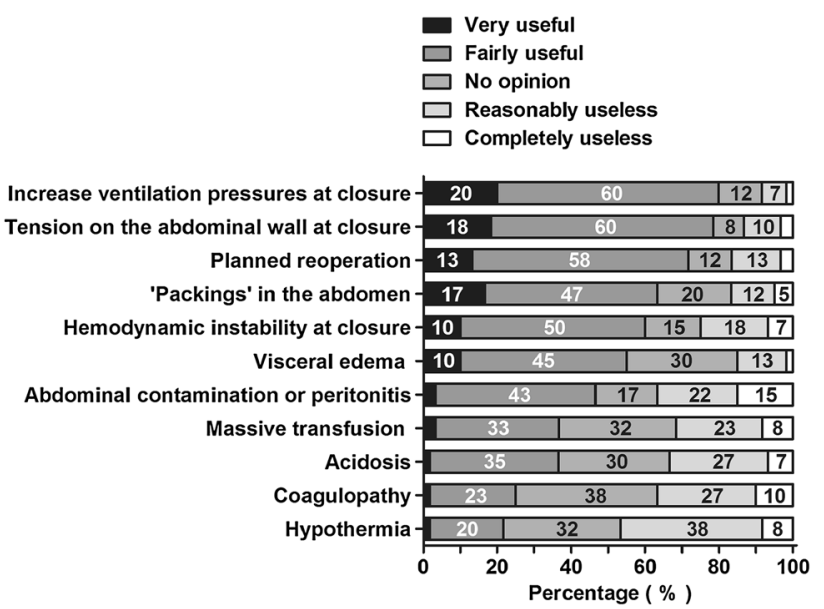

Fig. 9 Usefulness of factors in deciding not to close the abdomen after surgical decompression. Factors are arranged from highest to lowest summed percentage of very useful and fairly useful. Percentages of all respondents are shown in the bars

Table 5 Used temporary abdominal closure method or devices

\begin{tabular}{lcc}
\hline & $N$ & $\%$ \\
\hline Mesh placement $\left(\right.$ Vicryl $\left.^{\circledR}\right)$ & 38 & 63 \\
Bogota/silo bag & 28 & 47 \\
Abdominal VAC & 14 & 23 \\
Vacuum pack & 14 & 23 \\
Only closure of the fascia & 3 & 5 \\
Closure of the skin (with surgical clamps) & 3 & 5 \\
Closing of the skin with thick suture & 1 & 2 \\
Regular gauze cover & 1 & 2 \\
\hline
\end{tabular}

Percentages add up to more than $100 \%$ because respondents could select more than one answer

practice guidelines of this society are still waiting to be implemented in hospitals. Much disagreement exists today with respect to treatment and outcome of intra-abdominal hypertension and abdominal compartment syndrome among Dutch surgeons.

Ninety-five percent of respondents had previously treated a patient with ACS in their hospital. This was in line with the $97 \%$ reported by Tiwari et al. [12]. IAP measurements were regularly performed in $96 \%$ of the participating 
Table 6 Used definitive abdominal closure method

\begin{tabular}{lll}
\hline & $N$ & $\%$ \\
\hline Staged closure of the abdomen & 27 & 45 \\
Component separation technique & 26 & 43 \\
Absorbable mesh & 22 & 37 \\
Complete closure of fascia and skin & 21 & 35 \\
Only closure of the fascia & 20 & 33 \\
Non-absorbable mesh & 17 & 28 \\
ABRA system & 12 & 20 \\
Only closure of the skin & 5 & 8 \\
Delayed hernia & 1 & 2 \\
Dual mesh & 1 & 2 \\
Try to prevent non-resorbable materials & 1 & 2 \\
\hline
\end{tabular}

Percentages add up to more than $100 \%$ because respondents could select more than one answer

Table 7 Reply to statement: "Open abdomen treatment improves the outcome of patients with ACS"

\begin{tabular}{lcc}
\hline & $N$ & $\%$ \\
\hline Agree & 13 & 22 \\
$\begin{array}{l}\text { Agree, but open abdomen treatment is associated with many } \\
\text { complications }\end{array}$ & 46 & 77 \\
$\begin{array}{l}\text { Disagree, the complications outweigh the benefits of open } \\
\text { abdomen treatment }\end{array}$ & 1 & 2 \\
\hline
\end{tabular}

hospitals, which was markedly higher than the 31-47\% reported in other surveys $[4,5]$. The frequency of IAP measurements, however, varied greatly among hospitals. In 13 (23\%) hospitals, IAP was measured less than once per $24 \mathrm{~h}$. This frequency is rather low since IAP related morbidity can potentially develop or progress within a few hours [23].

There is still no consensus on the management of IAH and ACS. Although many respondents believed that IAH is only a symptom which does not necessarily needs to be treated, several different treatment options for IAH to prevent ACS were considered useful. For example, the use of diuretics and laparotomy are considered valuable. The majority of respondents were indifferent about other treatment options or regarded them as useless. This indifference about IAH treatment has previously been noted by Kimball et al. [2].

Most respondents ( $88 \%$ ) think that surgical decompression could prevent ACS and improve patient outcomes. This is markedly higher than the $60 \%$ of respondents who would recommend decompression laparotomy as reported by Zhou et al. [9]. Despite several indicators for surgical abdominal decompression were believed to be useful, $43 \%$ of our respondents felt the need for a superior indicator.

There is disagreement between respondents and literature regarding temporary abdominal closure (TAC) devices. Respondents reported to prefer mesh assisted TAC. Although evidence is not conclusive, literature slightly favors vacuum assisted techniques [24]. Definitive closure techniques ideally bring the edges of the abdominal fascia together primarily (primary closure). If this is not feasible, simple coverage or functional closure can be provided. These techniques are generally regarded as inferior with respect to patient outcome. Respondents seem to be aware of this, since they mostly preferred staged abdominal closure, followed by the component separation closure technique.

The vast majority of respondents were convinced of the necessity of open abdomen treatment for patients with imminent ACS, even though they were aware of the high complication rate associated with this treatment. They estimate that benefits of open abdomen treatment outweigh the chance of complications. This statement is confirmed by the presumed mortality reduction as result of open abdomen decompression as demonstrated in Fig. 9. The current study confirms there is a large support for this treatment, even though there is disagreement recent literature regarding the benefits of open abdominal decompression in pancreatitis patients with ACS [25, 26].

The strength of the current study is its robust methodology. The survey was based on previous questionnaires, was developed by an expert group, and was repeatedly pretested. Surgeons were kindly, but persistently urged to participate. The online software enables swift responding and easy data collection. The nationwide coverage of this survey is also considered a strength.

Taken into account the 10 incomplete responses, the response rate of $69 \%$ was fairly high. This number is at the upper end of response rates of the previously performed surveys on IAH and ACS (range 26-90 \%) [2-21].

The skewed distribution of the primary focus of respondents can be regarded a limitation of this study, but is representative of the clinical practice in The Netherlands. The overrepresentation of trauma surgeons and oncological surgeons may be the result of the connection between these sub-specializations and intensive care medicine. It was, however, not the intention to approximate a cross-section of all Dutch surgeons, but rather of the care patients actually receive. Assuming that patients will usually be treated by a physician with the most relevant knowledge and experience, we are convinced that the results of this study really demonstrate the awareness and knowledge of the surgeon with the largest relevant experience and knowledge. Another shortcoming is that the estimation of change in ACS occurrence over the last 10 years could be subject to recall bias. Although this was an important question, its outcomes were likely to be inaccurate. For example, six respondents indicated that a decrease in ACS incidence did not occur, while they ticked a lower number of 
cases category for last year compare than for 10 years ago (Table 2). However, this question does give insights in the perception of the experienced surgeon.

The overall knowledge and implementation of WSACS recommendations were lower than expected. This may be due to the fact that the vast majority of the respondents received their surgical training before the WSACS guidelines were developed. ACS treatment is currently implemented in these training programs. The results of the current study and the implementation in surgical training programs should result in increased awareness in the future.

In conclusion, the definitions of IAH and ACS and related diagnostic and therapeutic challenges are relatively well known among Dutch surgeons. Although use of the WSACS guidelines is currently limited, the willingness to do so is large. The vast majority of respondents are convinced of the necessity of open abdomen treatment for patients with imminent ACS, even though this treatment is associated with high complication rates. To decrease the complication rate, many respondents support the need for a superior indicator for surgical abdominal decompression.

Acknowledgments Prof.Dr. Roelf S. Breederveld (trauma surgeon, Rode Kruis Ziekenhuis, Beverwijk, The Netherlands), Dr. Desiree H. Burger (surgeon-intensivist, St. Elisabeth Ziekenhuis, Tilburg, The Netherlands), and Dr. Karel A. Kolkman (trauma surgeon, Rijnstate Ziekenhuis, Arnhem, The Netherlands) are acknowledged for their assistance and efforts as expert in drafting and pretesting the questionnaire.

IAH-ACS study group Bosma E (Martini Ziekenhuis, Groningen, The Netherlands), Breederveld RS (Rode Kruis Ziekenhuis, Beverwijk, The Netherlands), Breedveld PH (Academisch Ziekenhuis Maastricht, Maastricht, The Netherlands), Bronkhorst MWGA (MC Haaglanden Bronovo Nebo, Den Haag, The Netherlands), Buijk SE (IJsselland Ziekenhuis, Capelle a/d IJssel, The Netherlands), Burger DHC (St. Elisabeth Ziekenhuis, Tilburg, The Netherlands), Claassen ATPM (Twenteborg Ziekenhuis, Almelo, The Netherlands), Cleffken BI, (Maasstad Ziekenhuis, Rotterdam, The Netherlands), De Roos MAJ (Ziekenhuis Rivierenland, Tiel, The Netherlands), De Vries DP (Ommelander Ziekenhuisgroep, Delfzijl, The Netherlands), De Wit RJ (Medisch Spectrum Twente, Enschede, The Netherlands), Derom A (Zorgsaam Zeeuws-Vlaanderen, Terneuzen, The Netherland), Drixler T (Bravis Ziekenhuis, Bergen op Zoom, The Netherlands), Dwars BJ (Slotervaartziekenhuis, Amsterdam, The Netherlands), Eversdijk MG (Ziekenhuis St. Jansdal, Harderwijk, The Netherlands), Goslings JC (Academisch Medisch Centrum, Amsterdam, The Netherlands), Grevenstein WMU (UMC Utrecht, Utrecht, The Netherlands), Hammacher ER (St. Antonius Ziekenhuis, Nieuwegein, The Netherlands), Heetveld MJ (Kennemer Gasthuis, Haarlem, The Netherlands), Heres P, (Waterlandziekenhuis, Purmerend, The Netherlands), Kievit JK (Westfriesgasthuis, Hoorn, The Netherlands), Kloppenberg FWH (Ziekenhuis Bethesda, Hoogeveen, The Netherlands), Kolkman KA (Rijnstate Ziekenhuis,
Arnhem, The Netherlands), Leijtens JWA (Laurentius Ziekenhuis, Roermond, The Netherlands), Lettinga T (St. Jans Gasthuis, Weert, The Netherlands), Liem MSL (Deventer Ziekenhuis, Deventer, The Netherlands), Logeman F (Beatrix Ziekenhuis, Gorinchem, The Netherlands), Merkus JWS (HagaZiekenhuis, Den Haag, The Netherlands), Mulder J (Zaans Medisch Centrum, Zaandam, The Netherlands), Oprel P (Erasmus MC, Rotterdam, The Netherlands), Pierie JPEN (Medisch Centrum Leeuwarden, Leeuwarden, The Netherlands), Ploeg AJ (Diaconessenhuis, Leiden, The Netherlands), Punt BJ (Albert Schweitzer Ziekenhuis, Dordrecht, The Netherlands), Ritchie ED (Rijnland Ziekenhuis, Leiderdorp, The Netherlands), Schasfoort RA (Scheper Ziekenhuis, Emmen, The Netherlands), Schipper IB (Leids Universitair Medisch Centrum, Leiden, The Netherlands), Schmitz RF (Groene Hart Ziekenhuis, Gouda, The Netherlands), Simons MP (Onze Lieve Vrouwe Gasthuis, Amsterdam, The Netherlands), Sintenie JB (Elkerliek Ziekenhuis, Helmond, The Netherlands), Slooter GD (Máxima Medisch Centrum, Veldhoven, The Netherlands), Smakman N (Diakonessenhuis, Utrecht, The Netherlands), Smulders JF (Catharina Ziekenhuis, Eindhoven, The Netherlands), Sosef NL (Spaarne Ziekenhuis, Hoofddorp, The Netherlands), Staarink M (Van Weel-Bethesda Ziekenhuis, Dirksland, The Netherlands), Stevens CT (Bernhoven, Uden, The Netherlands), Tommee JH (Röpcke-Zweers Ziekenhuis, Hardenberg, The Netherlands), Van der Elst M (Reinier de Graaf Gasthuis, Delft, The Netherlands), Van der Kolk BM (Radboudumc, Nijmegen, The Netherlands), Van der Linden FThPM (St. Anna Ziekenhuis, Geldrop, The Netherlands), Van Geloven AAW (Tergooi Ziekenhuizen, Hilversum, The Netherlands), Van Helden SH (Isala Klinieken, Zwolle, The Netherlands), Van Marle AGJ (Vlietland Ziekenhuis, Schiedam, The Netherlands), Veltkamp SC (Ziekenhuis Amstelland, Amstelveen, The Netherlands), Verbeek PCM (Flevoziekenhuis, Almere, The Netherlands), Waleboer M (Admiraal De Ruyter Ziekenhuis, Goes, The Netherlands), Wieland AW (VieCuri Medisch Centrum, Venlo, The Netherlands), Zuidema WP (VU Medisch Centrum, Amsterdam, The Netherlands).

\section{Compliance with ethical standards}

Conflict of interest All authors (Steven G. Strang, Esther M.M. Van Lieshout, Roelof A. Verhoeven, Oscar J.F. Van Waes, and Michael H.J. Verhofstad) report no conflicts of interest relevant to this article. No funds were received by any of the authors in support of this study.

Ethical approval Since patients or animals were not involved in the study, the institutional Medical Research Ethics Committee did not have to review the protocol.

Informed Consent An informed consent procedure was not needed. Data were obtained from surgeons using a survey. The questionnaire was anonymous. An independent officer of data and privacy protection in our hospital reviewed the survey procedure and confirmed that participants' anonymity was protected.

Open Access This article is distributed under the terms of the Creative Commons Attribution 4.0 International License (http:// creativecommons.org/licenses/by/4.0/), which permits unrestricted use, distribution, and reproduction in any medium, provided you give appropriate credit to the original author(s) and the source, provide a link to the Creative Commons license, and indicate if changes were made. 
Appendix 1

\section{GENERAL INFORMATION}

1. What is your primary surgical focus? (multiple answers possible)

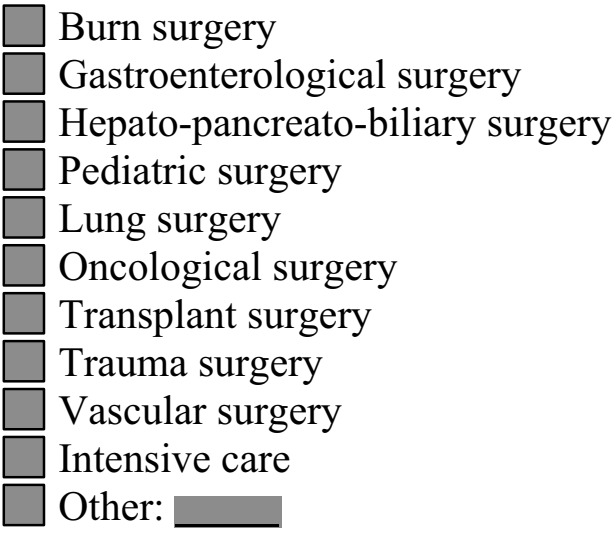

2. How many years of experience do you have as a trained surgeon?
$0-5$ year
$6-10$ year
$11-15$ year
Longer than 15 year

3. In which type of hospital are you particularly active?

Peripheral hospital without surgical training

$\square$ Peripheral hospital with surgical training

Academic hospital

4. Do you know the difference between intra-abdominal hypertension (IAH) and Abdominal Compartment Syndrome (ACS)?

$\square$ Yes

No

5. Have you ever seen a patient with ACS in your center?

$\square$ Yes 
6. Are intra-abdominal pressure measurements performed in your practice?

$\square$ yes (go to question 8)

$\square$ No

7. You indicated that intra-abdominal pressure measurements are not performed in your hospital, why not? (multiple answers possible)

$\square$ I'm not familiar with the intra-abdominal pressure measurement

$\square$ I do not know how the intra-abdominal pressure measurement is performed

$\square$ I do not know how to interpret the abdominal pressure

$\square$ I do not believe in the existence of intra-abdominal pressure-related diseases

I think that the intra-abdominal pressure measurement is not useful or relevant

Other:

\section{INTRA-ABDOMINAL PRESSURE MEASUREMENT}

8. How is the intra-abdominal pressure measurement performed in your hospital?

(Multiple answers possible)

$\square$ Intra-vesical

Intra-gastric

Intra-peritoneal catheter

9. How many times a day is the intra-abdominal pressure measurement performed in the individual patient?

$\square$ Less than one time a day

Once a day

Twice a day

Three times a day

Four times a day

$\square$ Six times a day

More than six times a day

A continuous intra-abdominal pressure measurement is used

10. In which patients would you perform IAP measurement more or less routinely?

Patients with or after (a/an)... (multiple answers possible)
Acute pancreatitis
Proven organ failure
Laparotomy
Massive fluid resuscitation of transfusion
Obesity
Patients on mechanical ventilation
Risk factors for increased intra-abdominal pressure
Emergency laparotomy
Suspected organ failure
Suspected abdominal compartment syndrome (ACS)
Other: 


\section{INTRA-ABDOMINAL HYPERTENSION (IAH)}

11. Which definition for IAH is used in your hospital? (not ACS)

An intra-abdominal pressure of $\geq 12 \mathrm{mmHg}$, as stated by the WSACS

No definition

Another definition, namely:

12. How useful do you consider the following treatments for IAH in order to prevent ACS?

Diuretics

Dialysis or CVVH

Laparotomy

Purging / enema administration

Paracentesis of the abdomen

Sedatives or neuromuscular blockade

Administration of more fluids

Administration of less fluids

Vasopression or inotropics

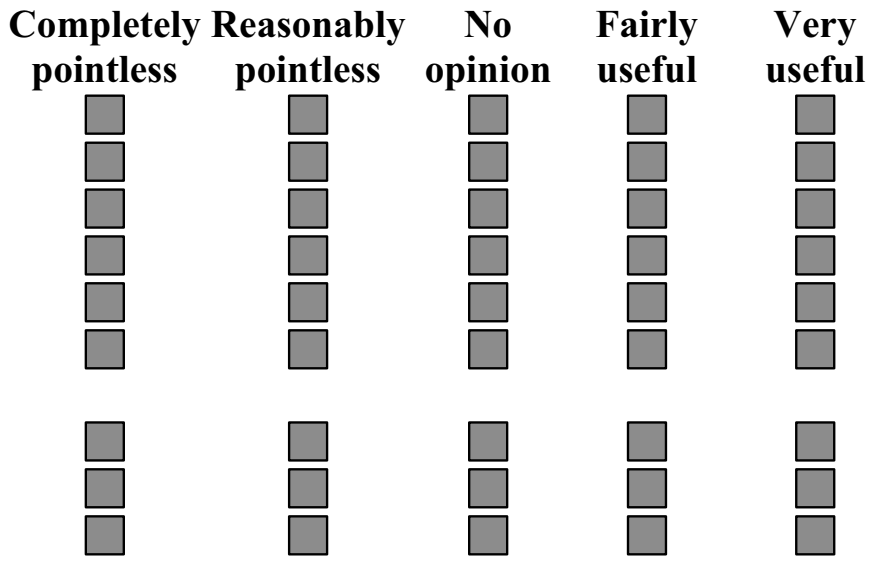

13. Do you agree with the following statement?

"IAH is only a symptom and requires no treatment in itself"

$\square$ Agree

Disagree

\section{ABDOMINAL COMPARTMENT SYNDROME (ACS)}

14. Which definition for ACS (not IAH) is used in your hospital? An IAP of:

$\square>20 \mathrm{mmHg}$
$\square>20 \mathrm{mmHg}$ with new organ dysfunction
$\square>25 \mathrm{mmHg}$
$\square>25 \mathrm{mmHg}$ with new organ dysfunction
$\square$ No specific definition is used
$\square$ Other:

15. How many patients with ACS were seen annually in your hospital 10 years ago (in your estimation)? Please use the "not applicable" box if you are not working in the same hospital anymore as 10 years ago.

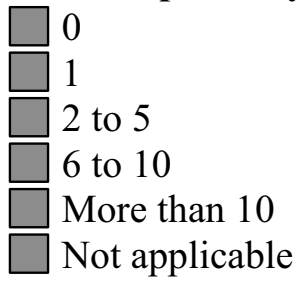


16. How many patients with ACS were seen the past year in your hospital (in your estimation)?

$\square 0$
$\square 1$
$\square$
2 to 5
$\square 6$ to 10
$\square$ More than 10

17. If there is an increase or decrease in the number of ACS cases, what do you think may have caused this?

$\square$ The increase or decrease is due to other developments

There is more awareness of ACS and its consequences

The therapy for ACS prevention has changed

Not applicable, an increase or decrease did not occur

Other:

18. The "World Society of the Abdominal Compartment Syndrome" (WSACS; www.wsacs.org) published consensus definitions and recommendations for treatment of Abdominal Compartment Syndrome. Are you familiar with this guidelines?
$\square$ Yes
$\square$ No

19. Is this guideline used in your clinic?

$\square$ Yes

No, but I would like to adopt any recommendations from the WSACS

$\square$ No, because these recommendations do not improve the outcome of the patient

No, there is no need for such a guideline

20. What percentage of patients with ACS in your hospital gets a surgical abdominal decompression?
$\square<10 \%$
$10-25 \%$
$26-50 \%$
$51-75 \%$
$76-100 \%$ 
21. How useful do you consider the following factors in deciding for surgical abdominal decompression (in addition to intra-abdominal pressure)?

Persistent or worsening acidosis Persistent or worsening oliguria Decreasing cardiac output Reduced abdominal perfusion pressure

Increasing oxygen demand Increasing ventilation pressures Increased lactate Elevated creatine kinase (CK)

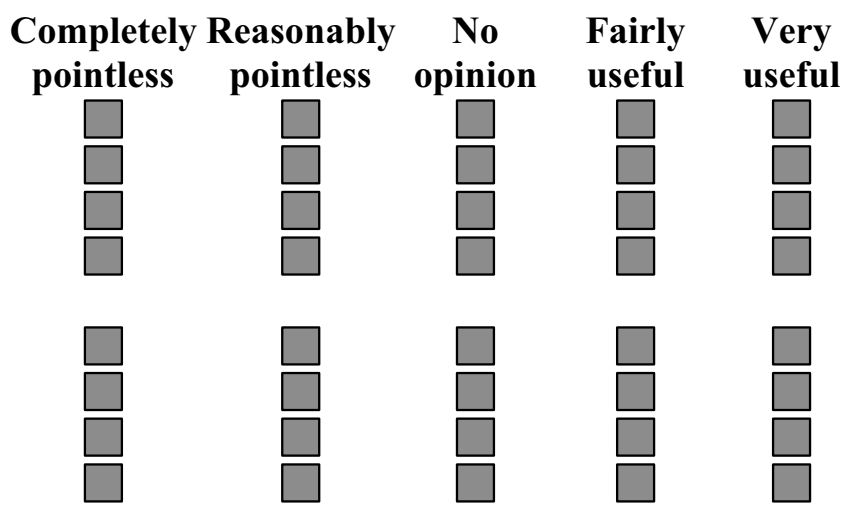

22. Is there a need for superior indicators for abdominal decompression in your hospital (for example a serum marker of hypoperfusion of abdominal organs)?

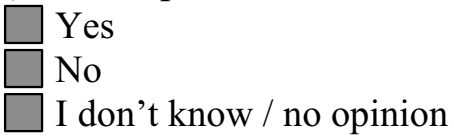

23. How high would you estimate the mortality of patients with ACS without abdominal decompression in your hospital?
$\square<10 \%$
$\square 10-25 \%$
$26-50 \%$
$51-75 \%$
$76-100 \%$

24. How high would you estimate the mortality of patients with ACS $\underline{\text { after abdominal }}$ decompression in your hospital?
$\square<10 \%$
$\square 10-25 \%$
$26-50 \%$
$51-75 \%$
$\square 76-100 \%$

\section{OPEN ABDOMEN TREAMENT AND ABDOMINAL CLOSURE}

25. Is ACS prevented by open abdominal treatment?

$\square$ Yes, always
$\square$ Yes, but not always
$\square$ No, never
$\square$ I'm not sure 
26. How useful do you consider the following factors in deciding not to close the abdomen following surgical decompression?

Abdominal contamination or

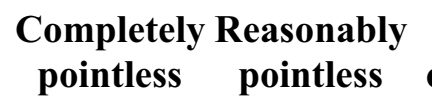

No

Fairly Very peritonitis

Acidosis

Coagulopathy

Planned reoperation

Hemodynamic instability at ointless opinion

useful

useful

closure

Hypothermia

Massive transfusion

'Packings' in the abdomen

Tension on the abdominal wall at closure

Increase ventilation pressures at

closure

Visceral edema

27. What temporary abdominal closure method or device would you use? (multiple answers possible)

Abdominal VAC

Only closure of the fascia

Always primary closure of fascia and skin

Bogota / silo bag

MESH placement $\left(\right.$ Vicryl $\left.^{\circledR}\right)$

Regular gauze cover

Closure of the skin (with terminals)

Vacuum pack (DSTC)

Other:

28. What definitive abdominal closure method would you use? (multiple answers possible)

$\square$ ABRA system

Absorbable MESH

Only closure of the skin

Only closure of the fascia

Component separation technique

Non-absorbable MESH

Staged closure of the abdomen

Complete closure of fascia and skin

Other: 


\section{Do you agree with the following statement? "The outcome van ACS patients improves with the use of open abdomen treatment" Agree Agree, but open abdomen treatment is associated with many complications Disagree, the complications outweigh the benefits of open abdomen treatment Disagree, open abdomen treatment even worsens the outcome of ACS patients}

\section{References}

1. Kirkpatrick AW, Roberts DJ, De Waele J, Jaeschke R, Malbrain ML, De Keulenaer B, Duchesne J, Bjorck M, Leppaniemi A, Ejike JC, et al. Intra-abdominal hypertension and the abdominal compartment syndrome: updated consensus definitions and clinical practice guidelines from the World Society of the Abdominal Compartment Syndrome. Intensive Care Med. 2013;39(7):1190-206.

2. Kimball EJ, Rollins MD, Mone MC, Hansen HJ, Baraghoshi GK, Johnston C, Day ES, Jackson PR, Payne M, Barton RG. Survey of intensive care physicians on the recognition and management of intra-abdominal hypertension and abdominal compartment syndrome. Crit Care Med. 2006;34(9):2340-8.

3. Kirkpatrick AW, Laupland KB, Karmali S, Bergeron E, Stewart TC, Findlay C, Parry N, Khetarpal S, Evans D. Spill your guts! Perceptions of Trauma association of Canada member surgeons regarding the open abdomen and the abdominal compartment syndrome. J Trauma. 2006;60(2):279-86.

4. De Laet IE, Hoste EA, De Waele JJ. Survey on the perception and management of the abdominal compartment syndrome among Belgian surgeons. Acta Chir Belg. 2007;107(6):648-52.

5. Burke BA, Latenser BA. Defining intra-abdominal hypertension and abdominal compartment syndrome in acute thermal injury: a multicenter survey. J Burn Care Res. 2008;29(4):580-4.

6. Otto J, Kaemmer D, Hoer J, Jansen M, Schumpelick V, Strik M, Kuhlen R, Schachtrupp A. Bedeutung des abdominellen Kompartmentsyndroms in Deutschland: Eine Umfrage. Anaesthesist. 2009;58(6):607-10.

7. Ejike JC, Newcombe J, Baerg J, Bahjri K, Mathur M. Understanding of abdominal compartment syndrome among pediatric healthcare providers. Crit Care Res Pract. 2010;2010:876013.

8. Costa S, Gomes A, Graca S, Ferreira A, Fernandes G, Esteves J, Costa A, Fernandes P, Casteloes P, Maciel J. Sindrome de compartimento abdominal: questionario sobre a sensibilidade dos cirurgioes gerais Portugueses. Acta Med Port. 2011;24(Suppl 2):131-6.

9. Zhou JC, Zhao HC, Pan KH, Xu QP. Current recognition and management of intra-abdominal hypertension and abdominal compartment syndrome among tertiary Chinese intensive care physicians. J Zhejiang Univ Sci B. 2011;12(2):156-62.

10. Nagappan R, Ernest D, Whitfield A. Recognition and management of intra-abdominal hypertension and abdominal compartment syndrome. Crit Care Resusc. 2005;7(4):298-302.

11. Ravishankar N, Hunter J. Measurement of intra-abdominal pressure in intensive care units in the United Kingdom: a national postal questionnaire study. Br J Anaesth. 2005;94(6):763-6.

12. Tiwari A, Myint F, Hamilton G. Recognition and management of abdominal compartment syndrome in the United Kingdom. Intensive Care Med. 2006;32(6):906-9.

13. Biancofiore G, Bindi ML. Measurement and knowledge of intraabdominal pressure in Italian Intensive Care Units. Minerva Anestesiol. 2008;74(1-2):5-8 (quiz 9).
14. Mayberry JC, Goldman RK, Mullins RJ, Brand DM, Crass RA, Trunkey DD. Surveyed opinion of American trauma surgeons on the prevention of the abdominal compartment syndrome. J Trauma. 1999;47(3):509-13 (discussion 13-4).

15. Karmali S, Evans D, Laupland KB, Findlay C, Ball CG, Bergeron E, Stewart TC, Parry N, Khetarpal S, Kirkpatrick AW. To close or not to close, that is one of the questions? Perceptions of Trauma Association of Canada surgical members on the management of the open abdomen. J Trauma. 2006;60(2):287-93.

16. Choi JY, Burton P, Walker S, Ghane-Asle S. Abdominal compartment syndrome after ruptured abdominal aortic aneurysm. ANZ J Surg. 2008;78(8):648-53.

17. MacLean AA, O'Keeffe T, Augenstein J. Management strategies for the open abdomen: survey of the American Association for the Surgery of Trauma membership. Acta Chir Belg. 2008;108(2):212-8.

18. Herrle F, Hasenberg T, Fini B, Jonescheit J, Shang E, Kienle P, Post S, Niedergethmann M. Offenes abdomen 2009. Umfrage zu Behandlungsstrategien des offenen abdomens in Deutschland. Chirurg. 2011;82(8):684-90.

19. Kaussen T, Steinau G, Srinivasan PK, Otto J, Sasse M, Staudt F, Schachtrupp A. Recognition and management of abdominal compartment syndrome among German pediatric intensivists: results of a national survey. Ann Intensive Care. 2012;2(Suppl 1):S8.

20. Newcombe J, Mathur M, Bahjri K, Ejike JC. Pediatric critical care nurses' experience with abdominal compartment syndrome. Ann Intensive Care. 2012;2(Suppl 1):S6.

21. Wise R, Roberts DJ, Vandervelden S, Debergh D, De Waele JJ, De Laet I, Kirkpatrick AW, De Keulenaer BL, Malbrain ML. Awareness and knowledge of intra-abdominal hypertension and abdominal compartment syndrome: results of an international survey. Anaesthesiol Intensive Ther. 2014. [Epub ahead of print] PubMed PMID: 25251947.

22. Bennett C, Khangura S, Brehaut JC, Graham ID, Moher D, Potter BK, Grimshaw JM. Reporting guidelines for survey research: an analysis of published guidance and reporting practices. PLoS Med. 2010;8(8):e1001069.

23. Rodas EB, Malhotra AK, Chhitwal R, Aboutanos MB, Duane TM, Ivatury RR. Hyperacute abdominal compartment syndrome: an unrecognized complication of massive intraoperative resuscitation for extra-abdominal injuries. Am Surg. 2005;71(11):977-81.

24. van Boele Hensbroek P, Wind J, Dijkgraaf MG, Busch OR, Goslings JC. Temporary closure of the open abdomen: a systematic review on delayed primary fascial closure in patients with an open abdomen. World J Surg. 2009;33(2):199-207.

25. Ke L, Ni HB, Tong ZH, Li WQ, Li N, Li JS. The importance of timing of decompression in severe acute pancreatitis combined with abdominal compartment syndrome. J Trauma Acute Care Surg. 2013;74(4):1060-6.

26. Mentula P, Leppaniemi A. Position paper: timely interventions in severe acute pancreatitis are crucial for survival. World J Emerg Surg. 2014;9(1):15. doi:10.1186/1749-7922-9-15 